\title{
Lucilia sericata'nın Lucimycin Geninin Moleküler Karakterizasyonu
}

\section{Molecular Characterization of Lucimycin Gene of Lucilia sericata}

\author{
Songül ÇETIN ${ }^{1}\left(\right.$ ID), Tülay AKSOY ${ }^{2}$ (ID) \\ ${ }^{1}$ Erciyes Üniversitesi Tıp Fakültesi, Tıbbi Parazitoloji Anabilim Dalı, Kayseri. \\ ${ }^{1}$ Erciyes University Faculty of Medicine, Department of Medical Parasitology, Kayseri, Turkey. \\ 2 İnönü Üniversitesi Tıp Fakültesi, Tıbbi Parazitoloji Anabilim Dalı, Malatya. \\ 2 Inonu University Faculty of Medicine, Department of Medical Parasitology, Malatya, Turkey.
}

\section{Makale Atıfı: Çetin S, Aksoy T. Lucilia sericata'nın lucimycin geninin moleküler karakterizasyonu. Mikrobiyol Bul} 2020;54(3):392-403.

\section{öz}

Calliphoridae ailesinin bir üyesi olan Lucilia sericata, Lucilia cinsindeki en yaygın türlerden birisidir. L.sericata'nın tıp açısından önemi, maggot debridman tedavisi (MDT)’nde kullanılmasından kaynaklanmaktadır. MDT, L.sericata larvalarının steril hale getirilerek iyileşmeyen yaraların tedavisinde kullanılmasına verilen isimdir. Kronik, iyileşmeyen yaraların (dekübit ülseri, venöz bacak ülseri, diyabetik ayak ülseri vb.) tedavisinde kullanılan L.sericata kurtçukları, salgıladıkları proteolitik tripsin ve lucimycin benzeri enzimler yardımıyla yaraları temizler. Bu çalışma, MDT'de görev alan L.sericata larvalarından moleküler yöntemler kullanılarak elde edilen lucimycin geninin moleküler karakterizasyonunu belirlemek ve literatüre katkıda bulunmak amacıyla yapılmıştır. Çalışma, L.sericata türüne ait erişkin kolonilerinin sürekli üretimi, ışık, nem ve sıcaklık gibi koşulların oluşturulduğu insektaryum ünitesinde yapılmıştır. L.sericata yaşam döngüsü takip edilerek, türüne ait yumurta, larva, pupa, erişkin sineklerin üretimi ve sinek kolonileri oluşturulmuştur. İnsektaryum ünitesinde ergin sineklerden elde ettiğimiz üçüncü dönem larvalardan RNA izolasyonu yapılmış ve takiben revers transkripsiyon ile cDNA sentezi gerçekleştirilmiştir. Sentezlenen cDNA'ların, L.sericata'nın lucimycin geni için tasarlanan özgül primerler ile polimeraz zincir reaksiyonu (PCR) analizi yapılmış ve elde edilen amplikonlar pJET1.2/blunt vektörüne klonlanarak plazmit saflaştırılmıştır. Elde edilen rekombinant plazmitlerin, vektöre özgül primerlerle dizi analizi yapılmış ve hedef gen bölgesi dizileri elde edilmiştir. Nükleotit dizileri saptanan izolatın moleküler karakterizasyonu belirlendikten sonra GenBank veritabanına MF964229 aksesyon numarası ile kaydı sağlanmıştır. İnsektaryum ünitesinde üretilen L.sericata larvalarından elde edilen CDNA'dan lucimycin özgül primerleri kullanılarak yapılan PCR sonucunda 288 baz çifti (bp) büyüklüğünde PCR ürünü elde edilmiştir. Agaroz jelde görüntülenen PCR ürünü, saflaştırılarak transformasyon işlemi yapılmış ve sonrasında oluşan kolonilerin rekombinant plazmit içerip içermedikleri PCR ile gösterilmiştir. Elde edilen kolonilerin üç tanesinin PCR ile L.sericata lucimycin geni içeren rekombinant plazmit olduğu tespit edilmiştir. PCR ile pozitifliği doğrulanan üç koloniden miniprep yapılarak L.sericata lucimycin geni içeren rekombinant plazmitler saflaştırılmıştır. Toplam $20 \mu \mathrm{l}$ rekombinant plazmit miniprep ürününe PCR uygulanarak rekombinant plazmit ürünün L. sericata lucimycin geni içerdiği doğrulanmıştır. Klonlama sonrası plazmitin doğrulanması amacıyla DNA dizi analizi yapılmıştır. DNA dizi analizi yapılarak 288 bp uzunluğundaki L.sericata lucimycin gen dizisi doğrulanmıştır. 
İzole ettiğimiz lucimycin genine, özgül pJET1.2 ileri ve revers primerler kullanılmak suretiyle çift yönlü dizi analizi uygulanarak sonuçlar Blastn algoritması ile tür ve/veya alt tür düzeyinde doğrulanmıştır. İzolat, MF964229 aksesyon numarası ile GenBank veri tabanına kaydedilmiştir. İzole ettiğimiz örneğimize ait DNA dizisi, Pubmed/Blast programı ile GenBank'ta bulunan diğer izolatlarla karşılaştııılmış ve KJ413251.1 GenBank nolu izolatla \%99 benzer bulunmuştur. İzolatımıza ait dizide 113. nükleotitin C (sitozin) olduğu görülürken, KJ413251.1 GenBank nolu izolattaki dizide ise G (guanin) olması iki dizi arasındaki farklılı̆ı ortaya koymuştur. Bu çalışma ile Türkiye'de ilk kez L.sericata larvalarından elde edilen lucimycin geninin moleküler karakterizasyonu yapılmış, elde edilen ve antifungal özelliğe sahip bu molekülün ileride gerçekleştirilecek olan özellikle kutanöz enfeksiyonlara neden olan mikroorganizmaları kapsayan çalışmalarda kullanılabileceği düşünülmüştür. Bu çalışma, Türkiye'nin biyolojik varlığı olarak GenBank'a kaydı yapılan izolat olması ve dünyada ikinci çalışma özelliği taşıması açısından önemlidir.

Anahtar kelimeler: Lucilia sericata; lucimycin; moleküler karakterizasyon.

\section{ABSTRACT}

Lucilia sericata, a member of the Calliphoridae family, is one of the most common species in the genus Lucilia. Medical importance of L.sericata stems from its use in maggot debridement therapy (MDT). MDT is the name of L.sericata larvae being sterilized and used in the treatment of non-healing wounds. L.sericata maggots used in the treatment of chronic and non-healing wounds (decubitus ulcer, venous leg ulcer, diabetic foot ulcer, etc.) clean the wounds with the help of secreted proteolytic trypsin and lucimycin -like enzymes. The aim of the study was to determine the molecular characterization of lucimycin gene obtained from L.sericata larvae in MDT by using molecular methods and to contribute to the literature. In this study, continuous production of adult colonies of L.sericata species was carried out in insectarium unit where conditions such as light, humidity and temperature were formed. The life cycle of L.sericata was followed and the production of eggs, larvae, pupae, adult flies and fly colonies of the species were formed. In the third stage larvae obtained from adult flies in the insectarium unit, RNA was isolated and subsequently CDNA synthesis was performed by reverse transcription. Polymerase chain reaction (PCR) analysis of the synthesized cDNAs with the specific primers designed for the lucimycin gene of L.sericata was performed and the obtained amplicons were cloned into pJET1.2/blunt vector and the plasmid was purified. The recombinant plasmids were sequenced with vector-specific primers and target gene region sequences were obtained. After the molecular characterization of the isolate with nucleotide sequences was determined, it was registered to GenBank database with the accession number MF964229. The PCR product of $288 \mathrm{bp}$ was obtained from the CDNA obtained from the larvae of L.sericata produced in the insectarium unit by PCR using lucimycin specific primers. The PCR product imaged on the gel was purified by transformation and subsequent colonies were screened to see whether they contained recombinant plasmids. Three of the colonies were identified as recombinant plasmids containing L.sericata lucimycin gene by PCR screening. From three colonies confirmed by PCR screening, recombinant plasmids containing L.sericata lucimycin gene were purified by miniprep. The recombinant plasmid product was confirmed to contain the L.sericata lucimycin gene by PCR from a total of $20 \mu \mathrm{l}$ of the recombinant plasmid miniprep product. DNA sequencing analysis was performed to confirm the plasmid after cloning. The 288 bp L.sericata lucimycin sequence was confirmed by DNA sequence analysis. The lucimycin gene isolated was confirmed by specific and pJET1.2 forward and reverse primers using Blastn algorithm as a result of species and/or subspecies using the Blastn algorithm and the related isolate was recorded in GenBank database with the MF964229 accessory number. The DNA sequence of the isolated sample was compared with other isolates found in GenBank by Pubmed/Blast program. KJ413251.1 was found to be $99 \%$ similar to the GenBank isolate. The $113^{\text {th }}$ nucleotide was C (cytosine) in the sequence of our isolate, while the existence of $\mathrm{G}$ (guanine) in the sequence numbered KJ413251.1 GenBank revealed the difference between the two sequences. In this study the molecular characterization of lucimycin gene derived from L.sericata larvae were determined for the first time in Turkey, it is assumed that this molecule which has an antifungal property, can be used in the studies that will be carried out in the future, especially in microorganisms causing cutaneous infections. The study is important since the isolate is registered as a biological asset of Turkey in GenBank and also being the second study in the world.

Keywords: Lucilia sericata; lucimycin; molecular characterization. 


\section{Gíriş}

Calliphoridae ailesinin bir üyesi olan Lucilia sericata, Lucilia cinsindeki en yaygın türlerden birisidir. Eskiden Phaenicia sericata olarak bilinen L.sericata yaygın olarak leş, çöp ve dışkı üzerinde bulunmaktadır ${ }^{1}$. L.sericata'nın tıp açııından önemi, maggot debridman tedavisi (MDT)'nde kullanılmasından kaynaklanmaktadır. MDT, L.sericata larvalarının steril hale getirilerek iyileşmeyen yaraların tedavisinde kullanılmasına verilen isimdir². Tıbbi tedavi amacıyla kullanılan kurtçuklar, yaralardaki enfeksiyonları ve nekrotik dokuları yok ederek yaraların iyileşmesine yardımcı olmaktadır ${ }^{3}$. MDT'nin etki mekanizması; nekrotik dokunun çıkarılması (debridman), yara iyileşmesinin hızlanması ve yara dezenfeksiyonu olmak üzere üç şekildedir ${ }^{4}$. Yara dezenfeksiyonunda, defensin benzeri lucifensin, kimotripsin gibi antibakteriyel aktiviteye sahip küçük moleküller ve antimikrobiyal peptitler (AMP) rol oynamaktadır. Bu önemli AMP'lerden biri de son zamanlarda tespit edilen ve aynı zamanda antifungal aktivite gösteren "lucimycin"dir.

Bu çalışmada, ergin L.sericata sineklerinin üçüncü dönem larvalarından elde edilen materyallerin moleküler yöntemlerle incelenerek, maggot tedavisinde yer alan L.sericata lucimycin gen bölgesine göre tasarlanmış özgül primerler ile moleküler olarak nitelendirilmesi amaçlanmıştır.

\section{GEREÇ ve YÖNTEM}

\section{L.sericata'nın Laboratuvarda Üretilmesi}

$\mathrm{Bu}$ çalışma, laboratuvarımızda bulunan insektaryum ünitesinde gerçekleştirildi. L.sericata türü sineklerin üretimi, $27-30^{\circ} \mathrm{C}$ sıcaklığa ve $\% 42-44$ bağıl neme sahip laboratuvarda \%20'lik şeker ve karaciğer parçaları verilerek yapıldı.

\section{Larvadan RNA İzolasyonu}

RNA izolasyonu yapmak amacıyla larvalar, bistüri yardımılla parçalandı ve 2 ml'lik mikrosantrifüj tüplerine aktarıldı. RNA izolasyonunu "Trigent RNA isolation reagent kit (Biomatik/K5161, ABD)" prosedürü optimize edilerek gerçekleştirildi. Elde edilen RNA'lar CDNA sentezinde kullanılmak üzere $-80^{\circ} \mathrm{C}^{\prime}$ de saklandı.

\section{cDNA Sentezi}

cDNA sentezi, "transkriptor high fidelity cDNA synthesis kit (Merck, Almanya)" prosedürü optimize edilerek uygulandı ve elde edilen cDNA, polimeraz zincir reaksiyonu (PCR)'nda kullanılmak üzere $-20^{\circ} \mathrm{C}^{\prime}$ de saklandı.

\section{Lucimycin Geninin Elde Edilmesi}

Çalışmada, lucimycin gen bölgesine ait özgül primerler tasarlandı ve PCR için Lucimycin F ve Lucimycin $R$ primerleri kullanıldı (Tablo I).

PCR için toplam $25 \mu$ l hacimde; $12.5 \mu \mathrm{l}$ master karışımı (SolisBioDyneFIREPol, Estonya), $3 \mu \mathrm{l}$ L.sericata cDNA'sl, $1 \mu \mathrm{l}$ Lucimycin F ve Lucimycin R primerleri ve $7.5 \mu \mathrm{l}$ steril distile su içerecek şekilde karışım hazırlandı. $95^{\circ} \mathrm{C}^{\prime}$ de 1 dakika ön ısıtma, $95^{\circ} \mathrm{C}^{\prime}$ de 30 saniye de- 


\begin{tabular}{llc}
\hline Tablo I. Lucimycin Gen Bölgesinin Amplifikasyonu lçin Kullanılan Primerler & \\
\hline Primer adı & Nükleotit dizisi & TM $\left({ }^{\circ} \mathrm{C}\right)$ \\
\hline Lucimycin F primer & (5'-CAC CAT GGC AAA ATT ATT TAT TAT TGT TCT TTT C-3') & 65.7 \\
Lucimycin R primer & (5'-TAA TAA CCA TGA CTT TTA TAG CCA TGA CC-3') & 64.8 \\
\hline
\end{tabular}

natürasyon, $62^{\circ} \mathrm{C}^{\prime}$ de 30 saniye primer bağlanması, $72^{\circ} \mathrm{C}^{\prime}$ de 30 saniye amplifikasyondan oluşan 35 döngü sonrası $72^{\circ} \mathrm{C}^{\prime}$ de 15 dakikalık son uzama işlemi yapıldı. PCR ürünü $\% 0.8$ etidyum bromür içeren \%1.5'lik agaroz jelde moleküler ağılık belirteci eşliğinde yürütüldü ve agaroz jeldeki bantlar chemiDoc MP system görüntüleme (Bio-Rad, ABD) cihazıyla görüntülendi.

Elde edilen PCR ürününün saflaştırılması için "Wizard SV gel and PCR clean-up system (Promega, $A B D)^{\prime \prime}$ protokolü optimize edilerek uygulandı. Saflaştırılmış PCR ürünü klonlama işlemine kadar $-20^{\circ} \mathrm{C}^{\prime}$ de saklandı.

\section{Lucimycin Geninin Klonlanması}

PCR ürününün klonlama işlemi, "CloneJET PCR cloning kit (Thermo Scientific, ABD)" prosedürüne göre gerçekleştirildi ve sonrasında lucimycin geni pJET vektörüne klonlandı. Bu karışımdan $5 \mu \mathrm{l}$ alınarak buz üzerinde bekletilen mikrosantrifüj tüpündeki $100 \mu \mathrm{l}$ kompetan OneShot ${ }^{\circledR}$ TOP10 Escherichia coli (Invitrogen, ABD) hücrelerine eklendi. Ardından mikrosantrifüj tüpü, $42^{\circ} \mathrm{C}^{\prime}$ de 1 dakika bekletilerek buz üzerine alındı ve üzerine $250 \mu \mathrm{SOC}$ (Super Optimal broth with Catabolit repression) besiyeri eklendi. Daha sonra ampisilinli katı Luria Bertani (LB) agar üzerine bu karışım ekildi ve $37^{\circ} \mathrm{C}^{\prime}$ de bir gece inkübe edildi. LB besiyerinde oluşan kolonilerin rekombinant plazmiti içerip içermediğini tespit etmek amacıyla PCR taraması yapıldı. PCR taraması ile transformasyon sonrasında oluşan kolonilerin rekombinant plazmiti içerip içermediği tespit edildi. Her bir koloni için $25 \mu$ l'lik karışım (master karışım $12.5 \mu \mathrm{l}$; Lucimycin F primeri $1 \mu \mathrm{l}$, Lucimycin R primeri $1 \mu \mathrm{l}$ ve steril distile su $10.5 \mu \mathrm{l}$ ) hazırlandı. Kolonilerden, steril pipet ucuyla alınan örnekler, tüplerdeki karışımlara eklendi. PCR protokolü uygulanarak elde edilen PCR ürünü, \%0.8 etidyum bromür içeren \%1.5'lik agaroz jelde moleküler ağırlık belirteci eşliğinde yürütüldü ve jel üzerindeki PCR ürünü "ChemiDoc MP system (Bio-Rad, $A B D)$ " görüntüleme cihazıyla görüntülendi.

PCR taraması ile pozitif olduğu belirlenen kolonilerden, "EZ-10 spin column plasmid DNA miniprep kit (Bio basic, Kanada)" protokolü uygulanarak miniprep hazırlandı ve L.sericata lucimycin genini içeren rekombinant plazmitler saflaştırıldı. Rekombinant plazmitler, kalıp olarak kullanılarak PCR yapıldı ve agaroz jelde görüntülenen L.sericata lucimycin geninin varlığı doğrulandı. Ayrıca, DNA dizi analizi yapılarak klonlamanın doğruluğu kesinleştirildi. DNA dizi analizi için pJET1.2 ileri sequencing primer (5'-CAC CAT GGC AAA ATT ATT TAT TAT TGT TCT TIT C-3') PJET 1.2 revers sequencing primer (5'-TAA TAA CCA TGA CTT TTA TAG CCA TGA CC-3') kullanıldı. Sonuçlar otomatik DNA dizi analiz cihazı (ABI PRISM 3130XL Genetic Analyzer, ABD)'nda analiz edildi. DNA dizi analizi sonuçları, Chromas v.1.45 programı ile http://blast.ncbi.nlm.nih.gov/ adresindeki BLAST (Basic Lo- 
cal Alignment Search Tool) programıla veri tabanında mevcut olan L.sericata dizileri ile karşılaştırılarak incelendi.

\section{BULGULAR}

Insektaryum ünitesinde üretilen L.sericata larvalarından elde edilen cDNA'dan lucimycin özgül primerler kullanılarak yapılan PCR sonucunda 288 bp büyüklüğünde PCR ürünü elde edilmiştir (Resim 1).

Agaroz jelde görüntülenen PCR ürünü bistüri ile kesilerek $1.5 \mathrm{ml}$ mikrosantrifüj tüpüne alınmış ve jelden Wizard ${ }^{\circledR}$ SV Gel and PCR Clean-UpSystem (Promega, ABD) kit prosedürüne göre saflaştırılmıştır. Saflaştııılan 288 bp büyüklüğündeki PCR ürünü \%0.8 etidyum bromür içeren \%1.5'lik agaroz jelde yürütülerek görüntülenmiştir (Resim 2).

Saflaştırılmış L.sericata lucimycin PCR ürünün $5 \mu$ l'si klonlamada kullanılmıştır. CloneJET PCR kit (Thermo Scientific, ABD) prosedürü optimize edilerek yapılan klonlamada, ligasyon sonucu elde edilen rekombinant plazmitin $3 \mu$ l'si One Shot $^{\circledR}$ Stbl3 ${ }^{\text {TM }}$ Chemically Competent E.coli (Thermo Fisher Scientific, ABD) hücrelerine transforme edilmiştir (Resim 3A). Transformasyon sonucu oluşan kolonilerin başka bir antibiyotikli LB besiyerine tek koloni ekimi yapılmıştır (Resim 3B).

Transformasyon sonrasında oluşan kolonilerin rekombinant plazmit içerip içermedikleri PCR taraması ile gösterilmiştir. Elde edilen kolonilerin üç tanesinin PCR taraması ile L.sericata lucimycin genini içeren rekombinant plazmit olduğu tespit edilmiştir (Resim 4).

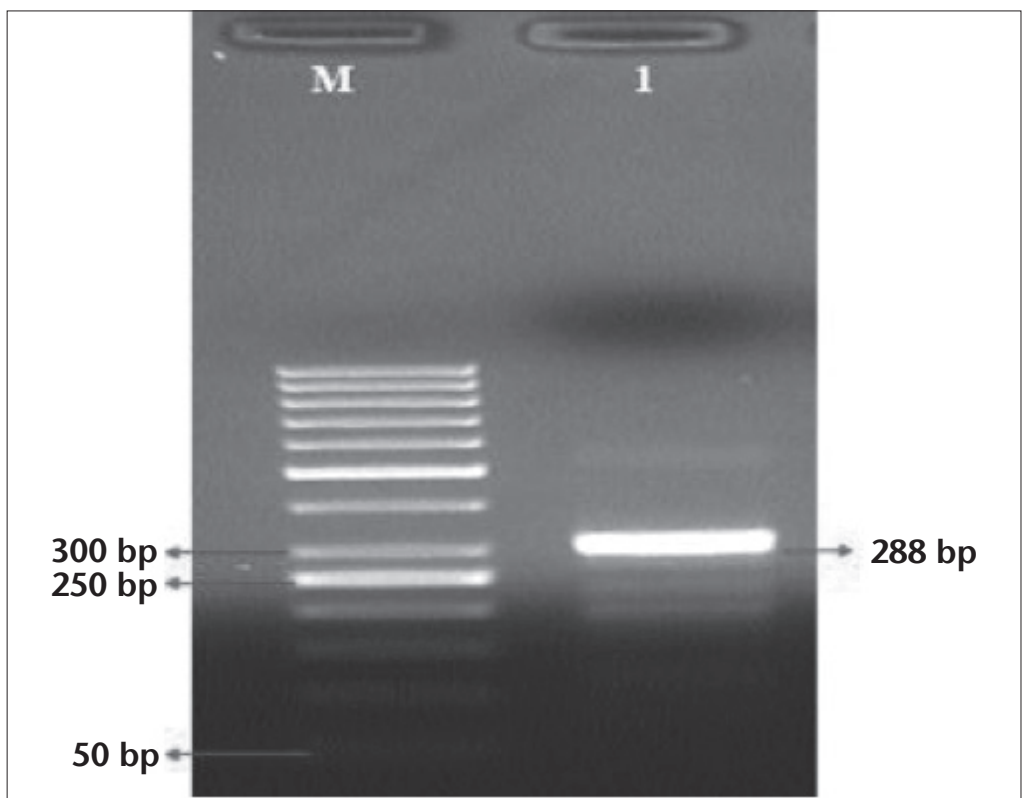

Resim 1. Lucilia sericata'nın 288 bp'lik lucimycin geninin \%1.5'lik etidyum bromür ile boyanmış agaroz jeldeki görüntüsü. 1: L.sericata örneği, M: Moleküler ağırık belirteci (50 bp). 


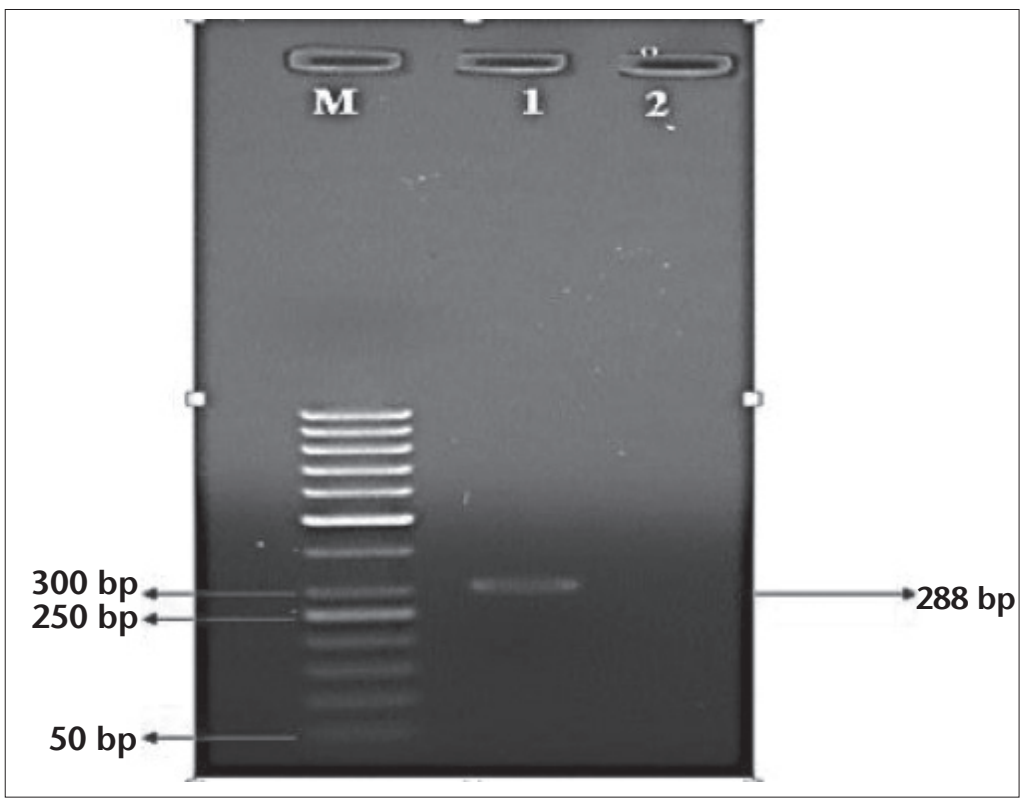

Resim 2. Lucilia sericata lucimycin geni clean-up sonrası PCR görüntüsü. 1: Clean-up sonrası lucimycin geni, 2: Negatif kontrol, M: Moleküler ağırlık belirteci (100 bp).
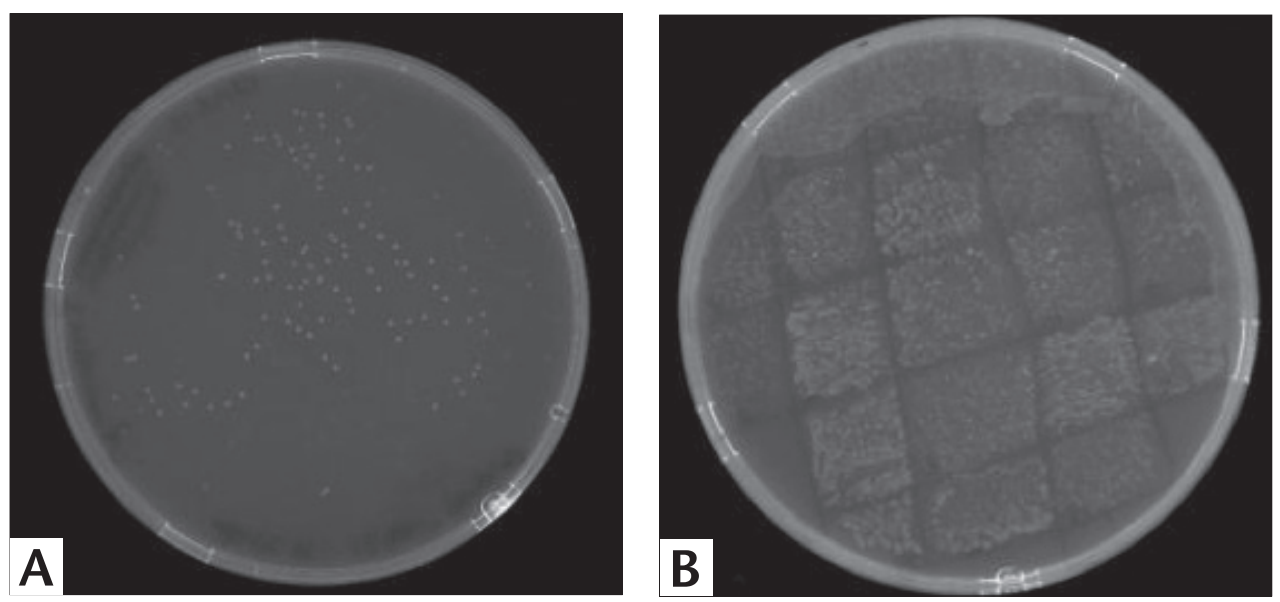

Resim 3. A. Transformasyon sonrası oluşan koloniler, B. Transformasyon basamağında ikinci inkübasyon sonucu oluşan koloniler.

PCR taraması ile pozitifliği doğrulanan üç koloniden miniprep (EZ-10 spin column plasmid DNA minipreps) kitine göre yapılarak L.sericata lucimycin geni içeren rekombinant plazmitler saflaştırılmıştır. Rekombinant plazmit miniprep ürününden toplam $20 \mu$ olacak şekilde PCR yapılarak rekombinant plazmit ürünün L.sericata lucimycin geni içerdiği doğrulanmıştır (Resim 5). 


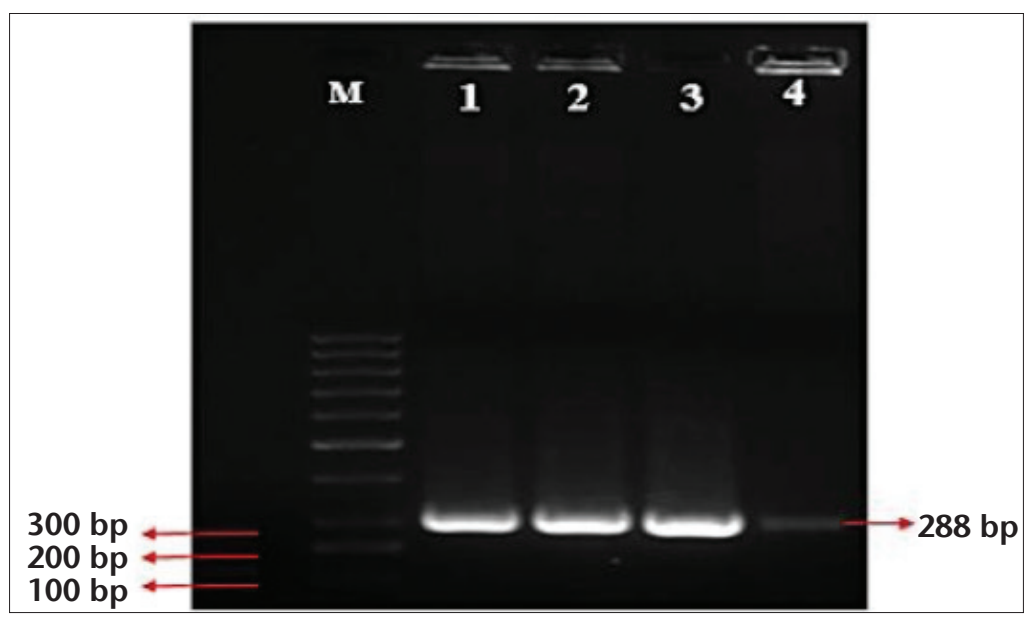

Resim 4. Inkübasyon sonucu çoğalan kolonilerden oluşturulan $P C R$ yöntemi ile pozitif çıkan örneklerin agaroz jelde görüntüsü. M: Moleküler ağırlık belirteci (100 bp Promega, $A B D), 1$, 2, 3: Pozitif koloniler, 4: Pozitif kontrol.

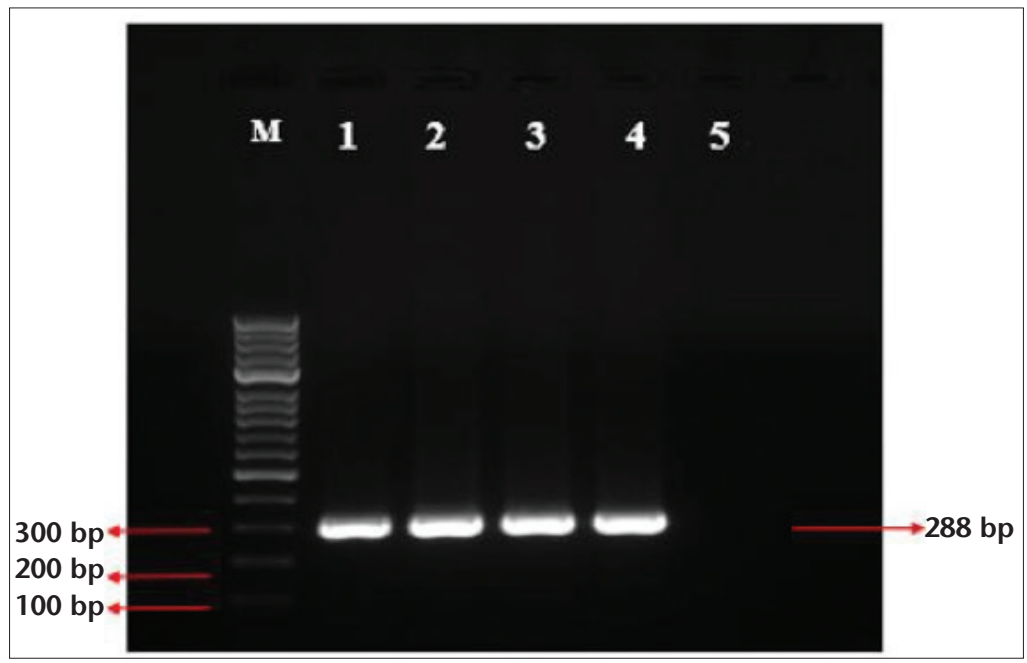

Resim 5. Lucilia sericata lucimycin miniprep PCR sonrası görüntüsü. 1: Pozitif kontrol, 2, 3, 4: Miniprep sonrası 288 bp'lik L.sericata lucimycin geni PCR ürünü, 5: Negatif konrol, M: Moleküler ağırlık belirteci (100 bp Promega, ABD).

Klonlama sonrası plazmidin doğrulanması amacıyla DNA dizi analizi yapılmıştır. DNA dizi analizi http://blast.ncbi.nlm.nih.gov/ internet adresinde yer alan web tabanlı BLAST (Basic Local Alignment SearchTool) (National Center for Biotechnology Information, ABD) programına girilmiştir. DNA dizi analizi yapılan 288 bp uzunluğundaki L.sericata lucimycin dizisi doğrulanmıştır (Şekil 1). Çalışmadan elde edilen DNA dizisi GenBANK veri tabanındaki mevcut L.sericata DNA dizileri ile karşılaştırılmıştır. 


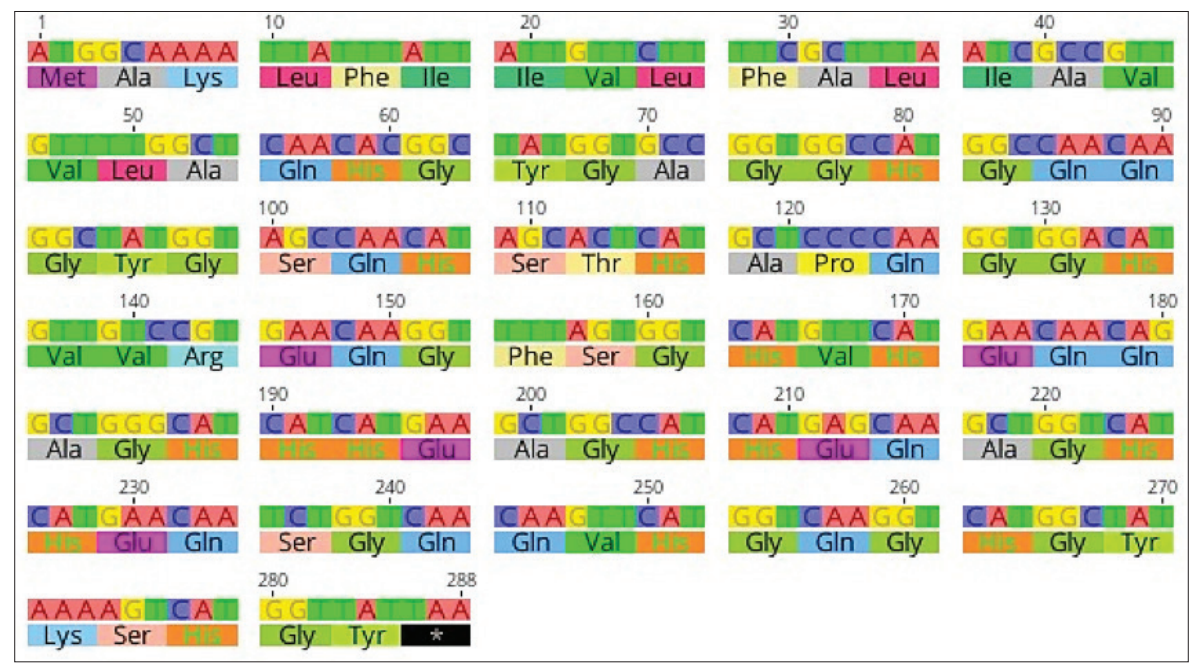

Şekil 1. DNA dizi analizi yapılan Lucilia sericata lucimycin gen dizisi.

İzole ettiğimiz lucimycin genini, spesifik pJET1.2 forward ve reverse primerleri ile çift yönlü olarak sekans analizleri sonucu Blastn algoritması kullanılarak tür ve/veya alt tür bazında konfirmasyonları sağlanmış olup ilgili izolat MF964229 aksesyon numarası ile GenBank veri tabanına kaydedilmiştir.

İzole ettiğimiz örneğimize ait DNA dizisi Pubmed/Blast programı ile GenBank'ta bulunan diğer izolatlarla karşılaştırılmıştır. KJ413251.1 GenBank nolu izolatla \%99 benzer olduğu görülmüştür. İzolatımıza ait dizide 113. nükleotitin C (sitozin) olduğu görülürken, KJ413251.1 GenBank nolu izolattaki dizide ise G (guanin) olması iki dizi arasındaki farklılığı ortaya koymuştur (Şekil 2).

\begin{tabular}{|c|c|c|c|}
\hline KJ413251.1 & & ATGGCAAAATTATTTATTATTGITCTTTTCGCTTTAATCGCCGTTGTTTTGGCTCAACAC & 60 \\
\hline MF964229 & 1 & 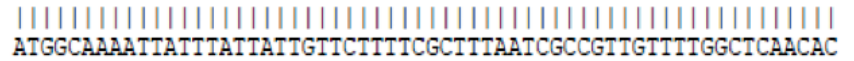 & 60 \\
\hline KJ413251.1 & 61 & 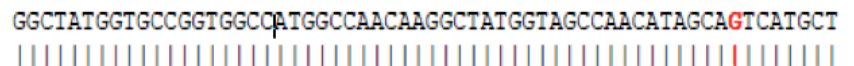 & 120 \\
\hline MF964229 & 61 & GGCTATGGTGCCGGTGGCCATGGCCAACAAGGCTATGGTAGCCAACATAGCACTCATGCT & 120 \\
\hline KJ413251.1 & 121 & $\begin{array}{l}\text { CCCCAAGGTGGACATGTTGTCCGTGAACAAGGTTTTAGTGGTCATGTTCATGAACAACAG } \\
\text {. }\end{array}$ & 180 \\
\hline MF964229 & 121 & CCCCAAGGTGGACATGTTGTCCGTGAACAAGGTTTTAGTGGTCATGTTCATGAACAACAG & 180 \\
\hline KJ413251.1 & 181 & 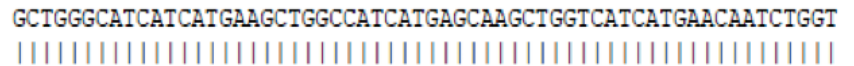 & 240 \\
\hline MF964229 & 181 & GCTGGGCATCATCATGAAGCTGGCCATCATGAGCAAGCTGGTCATCATGAACAATCTGGT & 240 \\
\hline KJ413251.1 & 241 & $\begin{array}{l}\text { CAACAAGTTCATGGTCAAGGTCATGGCTATAAAAGTCATGGTTATTAA } 288 \\
||||||||||||||||||||||||||||||||||||||||||||||)\end{array}$ & \\
\hline MF964229 & 241 & CAACAAGTTCATGGTCAAGGTCATGGCTATAAAAGTCATGGTTATTAA & \\
\hline
\end{tabular}

Şekil 2. Elde edilen Lucimycin geninin KJ413251.1 Genbank nolu izolatı ile karşılaştırılması. 


\section{TARTIŞMA}

İyileşmeyen kronik yaralara uygulanan en eski tedavi yöntemi MDT'dir. Tedavi ile ilgili yapılan laboratuvar ve klinik çalışmalarda, yaralar üzerine konulan kurtçukların nekrotik dokuyu ortadan kaldırdığı, granülasyon dokusunun oluşumunu hızlandırdığı ve enfeksiyondan arındırıp yeni bir enfeksiyon oluşumunu engellediği gösterilmiştir ${ }^{5}$. Önemli bir sağlık problemi olan inatçı kronik yaralarda, polimikrobiyal flora kolonize olmakta ve bu kolonizasyon yara iyileşmesini geciktirmektedir. Ayrıca, son yıllarda yapılan araştırmalarda, kronik yaraların antibiyotiklere karşı direnç oluşturduğu ve antibiyotiklerin mikrobiyal ajanlar üzerine olan etkisinin giderek azaldığı gösterilmiştir. Bu nedenle, antibiyotiklere yanıt vermeyen kronik yaralarda yeni ve etkili alternatif stratejilerin desteklenmesine gereksinim duyulmaktadır. MDT'de L.sericata'nın ikinci dönem larvaları kullanılmaktadır ${ }^{6}$. Çok uzun yıllardan beri kronik yaralara uygulanan L.sericata larvalarının etkin bir şekilde ölü dokuyu debride ettikleri ve yaralarda dezenfeksiyon sağladıkları kanıtlanmıştır. Bunun yanı sıra, tedavide kullanılan bu kurtçukların iyileşmeyi de hızlandırdıkları bilinmektedir ${ }^{7}$. MDT'de kullanılan larvalar canlı dokuyu etkilemeden, sadece nekrotik dokuları besin olarak kullanmaktadır. Bu larvalar yara üzerinde beslenmeleri sırasında ölü dokuları ayrıştırarak besin olarak kullanırlar. Bunun yanı sıra, yaradaki bakteri ve mantarları da besin olarak kullanabilmektedirler. Ayrıca, beslenme sırasında salgıladıkları enzimler sayesinde yaradaki mikroorganizmaları da ortadan kaldırmaktadırlar ${ }^{8}$.

Yara dezenfeksiyonunda, defensin benzeri lucifensin, kimotripsin gibi antibakteriyel aktiviteye sahip küçük moleküller ve antimikrobiyal peptitler (AMP) rol oynamaktadır. Bu önemli AMP'lerden biri de aynı zamanda antifungal aktivite gösteren lucimycindir ${ }^{9}$. Bu çalışmada, L.sericata'nın üçüncü dönem larvalarından lucimycin genine özgül primerlerle PCR ile elde edilen izolatın moleküler karakterizasyonu yapılmıştır. Larval sekresyonlardaki antimikrobiyal aktiviteye sahip olan moleküller, defensin benzeri bir molekül olan lucifensin ve kimotripsindir. Lucifensinin, L.sericata larvalarının salgı ürünlerinde bulunduğu ve yara patojenlerinin ortadan kaldırılmasında önemli bir rolünün olduğu düşünülmektedir. İlk defa larvaların bağırsağından izole edilen lucifensin daha sonra vücut yağlarında, tükürük bezinde ve hemolenfte de saptanmıştır ${ }^{5}$. Bir diğer antimikrobiyal ajan olan kimotripsin, larvaların debridman mekanizmasının anlaşılmasına yönelik çalışmalarda önemli bir noktayı aydınlatmaktadır. Kimotripsinin yara kabuklarını etkin bir şekilde azalttığı ve biyofilm tabakasının bozulmasında etkili olduğu görülmüştür. Biyofilm tabakasının bozulması ile birlikte bakteriler antibiyotiklere, immün sistem faaliyetlerine ve larva eylemlerine daha duyarlı hale gelmektedir ${ }^{6,9}$. L.sericata AMP'leri sadece lucifensin, kimotripsin ve lucimycin değil aynı zamanda attasin, sekropin, dipterisin, prolin açısından zengin peptitleri ve sarkotoksinleri de içermektedir ${ }^{10}$. Buna karşın, antifungal bir molekül olan lucimycin son yıllarda keşfedilmiş olup gelecekteki bilimsel çalışmalara da ışık tutacağı öngörülmektedir. Yapılan çalışmalarda yeni keşfedilen bu, sadece antifungal özelliğe sahip olduğu ve Oomycete, Ascomycota, Basidiomycota ve Zygomycota şubelerinin temsilcileri de dahil olmak üzere çeşitli mantar patojenlerine karşı etkinlik gösterdiği ortaya konmuştur. Lucimycinin antifungal mekanizması tam olarak bilinmemekle birlikte, muhtemelen bakte- 
riyel hücre zarlarının dış kısmında bulunan negatif yüklü fosfolipitleri bağlayan defensinler ve sekropinler gibi klasik katyonik peptitlerin antibakteriyel mekanizmalarından büyük ölçüde farklıdır. Bu peptitler bir amfipatik konformasyon benimseyerek bakteri membranında gözenek açabilmekte veya membranı bozabilmektedir. Lucimycinin hafif asidik olan pH'sı negatif yüklü olan membranlarla etkileşime girmediğini ve antibakteriyel aktivite eksikliği olduğunu açıklamaktadır ${ }^{11}$.

Pöppel ve arkadaşları tarafından gerçekleştirilen bir çalışmada ${ }^{12}$, antifungal bir peptit olan lucimycin transkriptinin tanımlanması, rekombinant ve sentetik üretimi, antibakteriyel ve antifungal etkinlik testleri yapılmıştır. Araştırmacılar bu çalışmalarında, lucimycin çoğu antimikrobiyal peptidin aksine disülfit bağlarına sahip olmadığını, prolin açısından zengin ve hidrofilik olduğunu fakat katyonik olmadığını göstermişlerdir. Araştırmacılar, tiyoredoksin ve His6 ile bir füzyon proteini olarak lucimycin üretmişlerdir. Daha sonra elde edilen rekombinant peptit saflaştırılarak in vitro ortamda antimikrobiyal etkinliklerini gözlemlemişlerdir. Illk olarak gram-negatif bakteriler olan E.coli, Pseudomonas aeruginosa ve gram-pozitif bakteriler olan Micrococcus luteus, Staphylococcus aureus ve Staphylococcus epidermidis'e karşı test etmişlerdir. Ancak lucimycinin bu bakterilere karşı test edilen en yüksek konsantrasyonda (100 $\mu \mathrm{M})$ bile aktivite göstermediğini gözlemlemişlerdir. Daha sonra ekonomik açıdan önemli tarımsal patojenler olan Fusarium raminearum ve Phytophthora parasitica'ya karşı in vitro ortamda 0.3-200 Mm lucimycin peptidinin varlığında çimlendirilen sporların sayısını belirleyerek antifungal etkinliğini test etmişlerdir. Test sonucunda lucimycinin çimlenme oranını düşürdüğü, hatta yüksek konsantrasyonlarda çimlenmeyi tamamen ortadan kaldırdığını gözlemlemişler ve lucimycinin antibakteriyel değil antifungal bir peptit olduğunu tanımlamışlardır.

Baumann ve arkadaşları "immün yanıt sırasında L.sericata dokularındaki özgül referans genlerin seçimi ve değerlendirilmesi" başlıklı çalışmalarında ${ }^{13}$ farklı patojen sınıflarını hedefleyen (18S rRNA, 28S rRNA, actin, $\beta$-tubülin, RPS3, RPLP0, EF1 $\alpha$, PKA, GAPDH ve GST1) 10 aday referans geni ve üç bağışık geninin (lucimycin, defensin-1 ve attacin-2), dokuya spesifik ekspresyon stabilitesini araştırmış ve P.aeruginosa ile L.sericata larvalarını enfekte edilerek immün yanıttan önce ve sonra farklı L. sericata dokularında bu üç bağışıklık geninin ekspresyonunu izlemişlerdir. Gram-negatif bakterileri hedefleyen attacin-2'nin larval dokularda azami düzeye ulaşan (50.000 kat üzerinde) güçlü etkisi görülmüştür. Ayrıca, gram-negatif bakterilere karşı hiçbir etkiye sahip olmadığı bilinen ve antifungal bir peptit olan lucimycinin beklenildiği gibi diferansiyel bir etkisine rastlanılmamıştır. Grampozitif bakterileri hedefleyen defensin-1'in ise şaşırtıcı şekilde larval dokularda yükseldiği gözlemlenmiştir.

DNA dizi analizi mikroorganizmalar arasındaki filogenetik ilişkileri belirlemek için kullanılan bir yöntemdir. Karşılaştırılan çok sayıda karakterin çözünürlük gücünü önemli derecede artırabileceği için filogenetik analizlerde DNA dizilerinin kullanılmasının yararIı olduğu bilinmektedir. Bu yöntem; dizide ortaya çıkan varyasyon şeklinin gözlenebilmesi yani bir mutasyonun transversiyon ya da transisyon tipinde veya sessiz (silent) ya 
da seçilmiş (selected) olup olmadığını anlamada aydınlatıcıdır. Ayrıca, nükleotit sapma derecesinin ölçülebilmesi, farklı laboratuvar sonuçlarının doğrudan karşılaştırılabilmesi, dizilerin yayımlanması ve elektronik veri tabanlarında saklanması (GenBank, EMBL ve DDBJ), sonuçların doğrulanması ve bu uygulamaların diğer taksonlara suş ya da klon elde etmeye gerek kalmaksızın uygulanabilmesi veya deneylerin tekrarlanabilmesine izin verecek özellikte olması DNA dizi analizinin önemli faydaları arasında yer almaktadır ${ }^{14,15}$.

Bu çalışma, dünyada GenBank'a kayıtlı ikinci, ülkemizde ise ilk kez L.sericata lucimycin DNA dizi bilgisini sunan bir çalışma olması açısından önemlidir. L.sericata larvalarından elde ettiğimiz izolatın lucimycin genine ait dizide 113. nükleotiti C iken, KJ413251.1 GenBank numaralı izolattaki dizi ile karşılaştırıldığında aynı pozisyondaki nükleotitin G olduğu görülmektedir. İki dizi arasındaki tek nükleotitlik fark çalışmamızda treonin (ACT) aminoasidine, Pöppel ve arkadaşlarının yaptığı çalışmada ${ }^{12}$ ise serin (AGT) aminoasidine denk gelmektedir. Yapılan analizler sonucunda coğrafyamızdaki L.sericata izolatının GenBank'a kayıtlı izolata \%99 oranında benzer olduğu görülmüştür. Bu çalışmada klonlanan genin ekspresyonu, proteinin saflaştırılması ve fonksiyonel olup olmadığı yönünde araştırma yapılmamış olması çalışmanın kısıtlııklarını ortaya koymaktadır. Bu nedenle, bu gen bölgesinin protein olarak ifade edilen bir bölge olması nedeniyle oluşan nokta mutasyonun fonksiyonel analizlerinin yapılması ileride yapılacak çalışmalara ön veri sağlayacaktır.

Sonuç olarak, bu çalışma ile L.sericata lucimycin genine ait rekombinant DNA dizisi elde edilmiştir. Çalışmada elde edilen ve antifungal özelliğe sahip bu molekülün ileride gerçekleştirilecek olan çalışmalarda özellikle kutanöz enfeksiyonlara neden olan mikroorganizmalarda kullanılabileceği düşünülmektedir.

\section{ETIK KURUL ONAYI}

Bu çalışma için etik kurul onayı gerekmemektedir.

\section{ÇIKAR ÇATIŞMASI}

Yazarlar bu makale ile ilgili herhangi bir çıkar çatışması bildirmemişlerdir.

\section{KAYNAKLAR}

1. Bazalinski D, Kozka M, Karnas M, Wiech P. Effectiveness of chronic wound debridement with the use of larvae of Lucilia sericata. J Clin Med 2019; 8(11): 1845.

2. Choudhary V, Choudhary M, Pandey S, Chauhan VD, Hasnani JJ. Maggot debridement therapy as primary tool to treat chronic wound of animals. Vet World 2016; 9(4): 403-9.

3. Purwins S, Herberger K, Debus ES, Rustenbach SJ, Pelzer P, Rabe E, et al. Cost of illness of chronic leg ulcers in Germany. Int Wound J 2010; 7(2): 97-102.

4. Zarchi K, Jemec GB. The efficacy of maggot debridement therapy a review of comparative clinical trials. Int Wound J 2012; 9(5): 469-77.

5. Jaklic D, Lapanje A, Zupancic K, Smrke D, Gunde-Cimerman N. Selective antimicrobial activity of maggots against pathogenic bacteria. J Med Microbiol 2008; 57(5): 617-25.

6. Bonn D. Maggot therapy: an alternative for wound infection. The Lancet 2000; 356(9236): 1174. 
7. Pöppel AK, Vogel H, Wiesner J, Vilcinskas A. Antimicrobial peptides expressed in medicinal maggots of the blow fly Lucilia sericata show combinatoria lactivity against bacteria. Antimicrob Agent Chemother 2015; 59(5): 2508-14.

8. Huberman L, Gollop N, Mumcuoglu KY, Breuer E, Bhusare SR, Shai Y, Galun R. Antibacterial substances of low molecular weight isolated from the blowfly, Lucilia sericata. Med Vet Entomol 2007; 21(2): 127-31.

9. Wiesner J, Vilcinskas A. Antimicrobial peptides: the ancient arm of the human immune system. Virulence 2010; 1(5): 440-64.

10. Thomas S, Jones M. Wound debridement: evaluating the costs. Nursing Standard 2001; 15(22): 59-61.

11. Ratcliffe NA, Mello, CB, Garci, ES, Butt TM, Azambuja P. Insect natural products and processes: new treatments for human disease. Insect Biochem Mol Biol 2011; 41(10): 747-69.

12. Pöppel AK, Koch A, Kogel KH, Vogel H, Kollewe C, Wiesner J, et al. Lucimycin, an antifungal peptide from the therapeutic maggot of the common green bottle fly Lucilia sericata. Bio Chem 2014; 395(6): 649-56.

13. Baumann A, Lehmann R, Beckert A, Vilcinskas A, Franta Z. Selection and evaluation of tissue specific reference genes in Lucilia sericata during an immune challenge. PLoS One 2015; 10(8): 1-16.

14. Kılıçoğlu M, Ozkoç I. Fungal sistematikteki moleküler gelişmeler. Omü Zir Fak Der 2008; 23(1): 65-72.

15. Yıldırım A, Bardakçı F, Karataş M, Tanyolaç B. Moleküler Biyoloji. Nobel Akademik Yay 2012; 2: 482-6. 